\title{
Coronavirus pandemic and cardiovascular issues
}

\author{
Koronavirüs pandemisi ve kardiyovasküler sorunlar
}

\author{
Şahin Şenay \\ Department of Cardiovascular Surgery, Acıbadem Mehmet Ali Aydınlar University, School of Medicine, Istanbul, Turkey
}

We have faced with a global health crisis since the beginning of 2020, and this situation was declared as a pandemic by the World Health Organization (WHO) on March $11^{\text {th }}, 2020$. We, as thoracic and cardiovascular surgeons together with perfusionists and nurses, are the essential components of the healthcare system who confront cardiovascular issues during this pandemic. The main concern for patients affected by the pandemic is underlying cardiovascular diseases, as the mortality increases dramatically in such conditions. The pandemic disease may have also direct or indirect cardiovascular complications such as acute myocardial injury/cardiac failure or myocarditis, arrhythmias, venous thromboembolism, and complex microvascular pathologies. Moreover, management strategies applied for the pandemic may have their own cardiovascular side effects which may require an additional treatment or intervention. Hence, we must reschedule operations and establish an optimum operational environment by preventing vulnerable patients and the surgical team, and must utilize hospital resources appropriately during this period.

Accordingly, the Turkish Journal of Thoracic and Cardiovascular Surgery (TJTCVS) has published two important reviews addressing some of these issues with an ahead-of-print alert. The first one covers mechanical circulatory support and the second one focuses on perioperative planning. Two editorial comments from our leading experts for these reviews are also included in this issue which detail the vascular and perfusionrelated issues. I would like to express my thanks all the contributing authors, editorial team, and our publishing group for their great efforts. Their rapid response to our call for assistance has an extreme value. I believe that these efforts will be invaluable for the care of our patients during the pandemic.

The efforts of the TJTCVS were in parallel with the rapid growth of pandemic literature during the last few weeks. Unfortunately, it is notable that many studies within the international literature include poor standards of reporting. This issue was also recognized by the European Association of Science Editors (EASE), which announced a statement alert on April $7^{\text {th }}, 2020$ emphasizing that the reports of research on this pandemic should meet required standards and comply with the agreed guidelines. Although rapid sharing of information is of utmost importance, particularly in such dreadful conditions, it should be kept in mind that reporting low-quality data may lead to misinterpretation and poor health care quality.

During this pandemic, the TJTCV will keep on increasing the quality of content and reaching more readers with higher standards. The trend of the journal data has been favorable so far. Our new article types have also gained a particular interest within the last term. Our download number per article has been on a rise, as well. Until now, the most downloaded material was a video article (Ozaki Procedure). We have received more submissions after the inclusion of our journal in PubMed Central (PMC). Also, there is a $25 \%$-increase in total submissions by the end of March 2020 on a monthly basis, compared to 2019 . We are particularly encouraged to see that the increase rate for international submissions is $55 \%$.

Received: April 15, 2020 Accepted: April 15, 2020 Published online: April 22, 2020

Correspondence: Şahin Șenay, MD. Acıbadem Maslak Hastanesi Kalp ve Damar Cerrahisi Bölümü, 34457 Maslak, ìstanbul, Turkey. Tel: +90 212 - 3044267 e-mail: sahinsenay@gmail.com 
Nevertheless, there is still a lot to do. Currently, we plan to decrease the total number of published papers with a rate of $10 \%$ consecutively in each issue for this year. We also plan virtual training programs for our reviewers focusing on evaluation of an article with participation of an international editorial faculty. These trainings will be also open for authors who are willing to be reviewers or editors in the future. These programs will be announced soon. We believe that these are important steps for improving the impact factor of our journal during the next couple of years.
Finally, I would like to announce that the Managing Editor of the thoracic section has recently changed and Ekber Sahin, MD has been assigned as the Editor. I would like to thank our previous Editor, Ayten Kayi Cangir, MD, for her great contributions the journal and to congratulate our newly elected Editor.

Our primary goal is to improve the scope and standards of the journal. We are open to any suggestions from our readers. We are aware of that the TJTCVS is strong with your support. Stay safe. 